\title{
EL DERECHO DE DEFENSA ADECUADA EN EL SISTEMA PENAL ACUSATORIO
}

\author{
The right to adequate defense in the criminal justice system \\ Christian Norberto HERNÁNDEZ AGUIRRE \\ A Manuel Vidaurri Aréchiga, amigo, guía acadé- \\ mico y destacado jurista de la Universidad de Gua- \\ najuato.
}

\begin{abstract}
"Aprender a trabajar en sistemas adversariales significa, fortalecer la capacidad del sistema judicial, de reconocer los intereses de las partes y, en ese sentido, "humanizarlo". La declamación, sólo realza la poesía. La declamación de principios que no se respaldan en herramientas de trabajo, sólo puede satisfacer a un narcisismo de lo "correcto", que degrada la lucha y la idea de la dignidad humana".
\end{abstract}

Alberto Binder

Sumario:

I. Introducción. II. El derecho de defensa adecuada y su regulación. III. El defensor. IV. La defensa técnica. V. La dogmática jurídica y su relación con el derecho de defensa. VI. Principios consubstanciales al derecho de defensa. VII. Inviolabilidad de la defensa para una "igualdad de armas". VIII. Conclusiones IX. Bibliografía.

Resumen: Este artículo plantea el derecho de defensa como una parte sustancial a las partes que se encuentren involucradas en el sistema penal, y analiza el riesgo de que se emprenda de manera deficiente sin un conocimiento dogmático y procesal, a lo que podría devenir un "efecto boomerang" para cualquier sujeto de derecho, por lo cual, es fundamental definir y comprender lo que es el derecho de defensa, su adecuada regulación tanto en el derecho sustantivo como en el derecho adjetivo, su relación consubstancial a las partes involucradas, la importancia de una defensa técnica y la inviolabilidad de la defensa que deben prevalecer en un proceso penal democrático.

Palabras clave: Derecho a la defensa, Derecho Procesal, Derecho penal, el debido proceso de ley.

Abstract: This paper discusses the right of defense as a substantial thing for the parts involved in a penal law suit, also makes an analysis of the risk that represents apply it without cientific and procedural knowledge, becoming in which we might call the "boomerang effect" for each subject of law, therefore becomes very important define and understand what right to defense is, also its right regulation in sustantive and adjective right, its consubstantial relation with the

1 Profesor de tiempo completo de la Licenciatura en Derecho, Facultad de Ciencias Administrativas y Sociales, de la Universidad Autónoma de Baja California y doctorando del doctorado interinstitucional en derecho por la Universidad de Guanajuato, Universidad Autónoma de Aguascalientes, Universidad de San Nicolás de Hidalgo de Michoacán y Universidad Autónoma de Nayarit, inscrito en esta última (2009-2012). 
parts involved, the importance of a technical defense and inviolability of the defense that should prevail in democratic criminal procedural law.

Keywords: Right to defense; criminal procedural law; technical defense; due process of law.

\section{INTRODUCCIÓN}

El presente trabajo, es con la idea de presentar un panorama general del derecho de defensa adecuada por la importancia de garantizarlo o maximizarlo en un proceso penal democrático. En palabras de Álex Carocca Pérez, en el ámbito del proceso, la defensa es reconocida como un derecho frente a un ataque previo de carácter jurídico, que específicamente en el proceso penal está constituido por la imputación o atribución a una persona determinada de la comisión de un hecho presuntamente delictivo. ${ }^{2}$ La defensa, en consecuencia, aparece en sus orígenes íntimamente ligada a la posibilidad de acción de actuación en pos de la tutela de un interés propio, que el sujeto considera digno de protección, pero con la esencial característica de que no se trata de una acción espontánea, sino motivada por la actuación previa de otro, que ha tomado la iniciativa. La defensa se entiende, más bien, como esa posibilidad de reacción en contra de una acción. Es en ese sentido como se procesaliza este instituto ${ }^{3}$

Podríamos afirmar, que es de suma importancia garantizar la defensa de los sujetos procesales, al ser base para el perfeccionamiento de la participación y contradicción dentro del sistema procesal como parte de sus derechos fundamentales, Vicente Gimeno, citado por Carocca Pérez, considera que por defensa debe entenderse a la parte procesal que viene integrada por la concurrencia de dos sujetos procesales, el imputado, y su abogado defensor. ${ }^{4}$ Es por ello, que se plantea al derecho a la defensa como un presupuesto importante en el sistema penal, que lleva consigo, la misma importancia para todas las personas que intervengan o no en el proceso, ya que, la finalidad de otorgar el derecho de defensa adecuada junto con otros principios como el de contradicción que le es inherente, es para contribuir a la igualdad de las partes en la búsqueda y valoración de los argumentos racionales dentro del enjuiciamiento penal.

Por lo anterior, es significativo abordar el estudio del derecho de defensa, entre los siguientes párrafos, en el que se contribuya al cambio de paradigma respecto al modelo paleopositivista del Estado legislativo de derecho que ha imperado, así como, para coadyuvar a la materialización del derecho de defensa, el cual, precisa no ser solamente un derecho ilusorio en las democracias modernas.

Por lo que el derecho de defensa se puede atender como un derecho fundamental y una garantía que se debe respetar, derecho que debe gozar todo ser humano. Siendo que, la defensa puede ser considerada como una garantía porque según enuncia Christian Courtis, "la noción de garantía se refiere, justamente, a aquellos métodos, mecanismos o dispositivos, que sirven para asegurar la efectividad de un derecho. Se trata de instrumentos para que ese derecho declarado en el papel se convierta en un derecho operable, ejecutable, exigible."5 y

${ }^{2}$ CAROCCA PÉREZ, Álex, Manual el nuevo sistema procesal penal, 3ra. ed., Chile, Lexis Nexis, 2005 p. 85.

3 CÁRDENAS RIOSECO, Raúl F., El derecho de defensa en materia penal, su reconocimiento constitucional, internacional y procesal, 2a. ed., México, Porrúa, 2009, p. 2.

${ }^{4}$ Ibídem, p. 10.

5 COURTIS, Christian, Miguel CARBONELL (comp.), "Los derechos sociales en perspectiva: la cara jurídica de la política social", Teoría del neoconstitucionalismo, Madrid, Editorial Trotta, 2007, p. 196. 
que según Héctor Fix- Zamudio, "es el medio, como su nombre lo indica, para garantizar algo, hacerlo eficaz o devolverlo a su estado original en caso de que haya sido tergiversado, violado, no respetado," ${ }^{\mathrm{y}}$ así mismo puede ser considerado como un derecho fundamental, porque según palabras de Ferrajoli respecto a los derechos fundamentales aduce que "son todos aquellos derechos subjetivos que corresponden universalmente a los seres humanos en cuanto dotados del status de personas de ciudadanos o de personas con capacidad de obrar", así mismo, Robert Alexy menciona que los derechos fundamentales "son mandatos de optimización, como tales, son normas de principio, que ordena la realización de algo en la más alta medida, relativamente a las posibilidades fácticas y materiales" ${ }^{8}$, por lo que el derecho de defensa, visto como un derecho fundamental y como una garantía constitucional, precisa seguir su estudio e interpretación para asegurar su protección y contribuir a la optimización de su eficacia frente a un ataque previo de carácter jurídico.

\section{EL DERECHO DE DEFENSA ADECUADA Y SU REGULACIÓN}

La regulación del derecho de defensa al concebirse como un derecho de rango fundamental, atribuido a las partes de todo proceso, podemos decir que se puede materializar básicamente en la necesidad de que estas sean oídas, en el sentido de que puedan alegar y puedan demostrar para conformar la resolución judicial, y en que conozcan y puedan rebatir sobre todos los materiales de hecho y de derecho que puedan influir en la resolución judicial.

En palabras de Joan Picó I Junoy, "la vigencia del derecho a la defensa asegura a las partes la posibilidad de sostener argumentalmente sus respectivas pretensiones y rebatir los fundamentos que la parte contraria haya podido formular en apoyo de las suyas, pero sin que sea necesario que de facto tenga lugar una efectiva controversia argumental entre los litigantes, que, por unas u otras razones, puede no producirse." 9 Por lo que en palabras de Juan Luis Gómez Colomer, "el principal derecho del acusado es el de defensa, correlativo a la acusación, como la concreción del principio de contradicción, tanto en su vertiente material, como técnica a cargo del defensor. El cambio del sistema inquisitivo al acusatorio se nota de manera especialmente incisiva en este derecho, pues en verdad en un proceso inquisitivo el acusado no tiene prácticamente derecho a nada, tampoco a defenderse, aunque de manera formal aparezca este derecho consagrado en la ley, ya que, la acusación se teje de manera secreta en su contra, no teniendo obligación las autoridades públicas de persecución de recoger las pruebas exculpatorias, cercenando además, las posibilidades de actuación real del defensor." ${ }^{\prime 10}$

De ahí entonces, podemos decir que el derecho de defensa junto con el contradictorio o contradicción es esencialmente la manifestación técnica en el proceso de la garantía consti-

\footnotetext{
${ }^{6}$ FIX-ZAMUDIO, Héctor, Eduardo FERRER MAC-GREGOR, (coord.), "Breves reflexiones sobre el concepto y contenido del derechos procesal constitucional”, Derecho procesal constitucional, 4a. ed., México, D.F., Porrúa., 2003, t. I, pp., 273.

7 FERRAJOLI, Luigi, Derechos y garantías. La ley del más débil, 4a. ed., trad. Perfecto Andrés Ibáñez y Andrea Greppi, Madrid, Editorial Trotta, 2004, colección Estructuras y Procesos, p. 37.

8 ALEXY, Robert, Teoría de los derechos fundamentales, 2a. ed., trad. Carlos Bernal Pulido, Madrid, Centro de Estudios Políticos y Constitucionales, p. 651.

9 PICÓ I Junoy, Joan. Las garantías constitucionales del proceso, Barcelona, José María Bosch Editor, 20o8, p. 102.

${ }^{10}$ GÓMEZ COLOMER, Juan-Luis, El sistema de enjuiciamiento criminal propio de un Estado de Derecho, México D. F., Instituto Nacional de Ciencias Penales, 2008, p. 204.
} 
tucional y legal de la defensa, ya que, es a través del contradictorio donde se logra la fórmula mediante la cual se articula técnicamente en el proceso, el derecho fundamental a la defensa. Para no confundirse entonces la causa con la consecuencia, lo correcto es afirmar que el contradictorio (efecto), deriva de la consagración del derecho a la defensa." ${ }^{11}$

Por lo que la garantía de defensa en todo el establecimiento del orden jurídico estatal, y sobre todo, en la regulación de las relaciones sociales que se concreta con el pleno y correcto ejercicio de la contradicción entre los sujetos procesales. La defensa que es garantía constitucional y derecho fundamental, y por tanto derecho irrenunciable e inalienable, tiene que ser total, es decir, plena, continua y permanente, durante toda la actuación procesal: pesquisas previas o preliminares, instrucción o investigación y juicio." ${ }^{12}$ Ya que, solamente gozando del derecho de defensa y respetándose el derecho fundamental a la defensa por todas y cada una de las partes, se podría decir que están garantizados los derechos por igual entre las mismas partes intervinientes, y sobre todo, al acusado vulnerado de sus garantías como en las prácticas del modelo inquisitivo o inquisitivo mixto que ha estado en innumerables casos, por lo que ha sido imposible acercarnos a esa utopía de gozar de un derecho de defensa adecuado y regulado de manera efectiva.

Por lo que en palabras de Mauricio Pava Lugo "el derecho de toda persona gente o ente, de poder expresar sus razones frente a su eventual contradictor o derecho a ser oído no solo exige un hábitat adecuado a su naturaleza y operatividad seguridad jurídica sino también y básicamente, el ecosistema de garantías, a través del cual, funcionan las indispensables interacciones recíprocas entre ambos. El derecho a ser oído constituye un componente fundamental del derecho de defensa y se erige en derecho humano esencial y por tanto, elemento visceral de un justo proceso constitucional. El derecho a ser oído es constitutivo de un principio irrenunciable del derecho procesal constitucional que se expande, desde la norma cimera y su bloque, hacia todas las exteriorizaciones procedimentales, pudiendo desarrollarse excepciones razonables en orden a su tiempo y modo de concreción."13

El derecho de defensa, núcleo esencial del debido proceso, se encuentra conformado por el derecho a ser oído, con el pleno de sus garantías constitucionales, y el derecho a guardar silencio, es decir, su derecho a callar, así como a dar su propia versión sobre los hechos en ejercicio pleno de su derecho de defensa. ${ }^{14}$

Alberto Binder aduce "que el poder sancionador del Estado constituye la amenaza concreta de aplicación de una pena de encierro y de sufrir los demás costos personales que apareja el solo hecho de verse sometido a un proceso penal. La historia de la persecución penal ha sido pródiga en arbitrariedades e injusticias y por tal razón se fue consolidando el lugar del derecho a defenderse ante toda imputación de un delito como uno de los derechos fundamentales en defensa de la libertad de todos los ciudadanos. La larga lucha por la consolidación de este derecho se materializa hoy en las fórmulas normativas que los Pactos Internacionales de Derechos Humanos y las Constituciones de todos los países. Ya no que-

\footnotetext{
${ }^{11}$ ARISTIZABAL BOTERO, Luis Ignacio, Contradicción o controversia de la prueba en materia penal, Bogotá D. C., Leyer, 2001, p. 125.

${ }^{12}$ CHOWELL ARENAS, Daniel Federico, Los principios del proceso penal. Su regulación y su realidad en el estado de Guanajuato, Guanajuato, Universidad de Guanajuato, 2008, p. 82.

${ }^{13}$ PAVA LUGO, Mauricio, La defensa en el sistema acusatorio, Bogotá D. C., ediciones jurídicas Andrés Morales, 2009, pp. 138-139.

14 Ibídem, p. 140.
} 
dan dudas de que la posibilidad real de defenderse de la persecución penal constituye una garantía inherente al Estado de Derecho." ${ }^{15}$

De este modo, la defensa constituye no solo una garantía constitucional, sino también una condición de legitimidad y validez de los procesos penales en todas sus etapas. La posibilidad de que exista una defensa real disminuye el margen de error en las intervenciones del sistema penal, otorgándole mayores posibilidades de acercarse en sus decisiones a la verdad por el litigio y la controversia de las partes, en lugar de dejar librado todo el desarrollo del proceso a la actividad unilateral del juez. ${ }^{16}$

En la ideología liberal de los derechos fundamentales, el derecho a defensa tiene su fundamento en el reconocimiento de la autonomía individual. Su objetivo final es que el imputado tenga la posibilidad material de incidir en el resultado del proceso. Es por ello, que dentro del derecho de defensa, encontramos expresiones que no solamente ponen un límite al poder estatal, sino que buscan dar al imputado un espacio de decisión sobre su propia suerte. Una de las garantías del derecho de defensa en que encontramos una expresión de la autonomía individual es el derecho a guardar silencio, entendido como la capacidad de dominar de un modo absoluto la información que el imputado desea ingresar al juicio (señorío sobre su declaración). Es decir, el derecho de defensa, principalmente, el derecho de defensa del imputado, es el reconocimiento de su calidad de sujeto del proceso y no de un objeto, ni siquiera un objeto de protección. ${ }^{17}$

El Estado debe fundar y motivar sus actuaciones con base en argumentos y razones empleadas y deducidas de los sujetos procesales, lógica y jurídicamente, formando convicción para llegar a la verdad forense, y no restringir los derechos fundamentales, como el de la garantía de defensa y su consecuencia, en las actuaciones donde se ejerza el principio de contradictoriedad por los sujetos procesales en un plano de igualdad, para legitimar así su actuación y derecho a ejercer el derecho a castigar.

La controversia, resulta consustancial al derecho de defensa, sus orígenes históricos se remontan a la época de la ilustración y tiene dos entornos: uno probatorio, que se contrae tanto a la prueba como al valor cognitivo que le dispensa el funcionario a cada probanza, y desde la perspectiva sustancial, comporta el derecho a controvertir argumentalmente lo planteado por la otra parte, frente a la sustancia de lo que se debate en el juicio. Hay que decir igualmente, que es un derecho de todos los intervinientes en la audiencia y no exclusivamente de propiedad del acusado y su defensor porque apunta a la protección de los intereses de todas las partes. La controversia asegura la imparcialidad del juzgador ya que la discusión entre las partes opuestas en el proceso, que obran en igualdad de condiciones, enriquece el debate y da más luces y posibilidades al juez que recibe la prueba de manera directa y personal sobre hecho que se reconstruyó en la vista pública. ${ }^{18}$

Las injerencias estatales dentro de los procedimientos penales principalmente lesionan derechos como el de la dignidad e integridad moral, el de la libertad, el de la intimidad y todos sus derivados de carácter fundamental. Por lo que en palabras de Mauricio Pava Lugo "los motivos fundados se constituyen en una "salvaguarda jurisdiccional" que protegen al

\footnotetext{
${ }^{15}$ BINDER, Alberto et al., Manual de defensoría penal pública para América Latina y el Caribe, Santiago, Alfabeta artes gráficas, 1985, p. 19.

${ }^{16}$ Ibídem, p. 20.

${ }^{17}$ Ibíd., p. 21

${ }^{18}$ ARIAS, Juan Carlos y CALDERÓN, Henry, Axiología y deontología del proceso penal y el precedente judicial, Colombia, Checchi And company consulting, 2002, p. 55.
} 
ciudadano en el marco de una acción penal de injerencias estatales arbitrarias en su contra, por ello, los motivos fundados no corresponden a un exclusivo juicio subjetivo del operador judicial (Juez, Fiscalía, autoridad policiva en tal rol funcional) sino que por el contrario requieren de un patrón probatorio objetivo y reflejado en la motivación antecedente o precedente (según el tipo de control judicial exigido-anterior o posterior) del acto de injerencia estatal."19

La facultad de controvertir la existencia de motivos fundados no solo es una posibilidad sino un derecho exigible por quien es o ha sido objeto de restricción de sus derechos fundamentales dentro de una acción penal que se surta en su contra; puesto que de poco le sirve a un ciudadano tener un derecho o estar protegido por una salvaguardia jurisdiccional si no se le concede la facultad o la opción para exigirlo; esta facultad se encuentra inmersa en el derecho a la defensa que constitucionalmente se prevé a lo largo y ancho de la acción penal sin que su fragmentación en fases pre-procesales o procesales permitan su exclusión. ${ }^{20}$

En palabras de Ferrajoli, la garantía de la defensa consiste precisamente en la institucionalización del poder de refutación de la acusación por parte del acusado. Conforme a ella, para que una hipótesis acusatoria sea aceptada como verdadera no basta que sea compatible con varios datos probatorios, sino que también, hace falta que no sea contradicha por ninguno de los datos virtualmente disponibles. A tal fin, todas las implicaciones de la hipótesis deben ser explicitadas y ensayadas, de modo que sean posibles no sólo las pruebas sino también las contrapruebas. Y la búsqueda de éstas debe ser tutelada y favorecida no menos que la búsqueda de aquéllas. Evidentemente, ni siquiera las contrapruebas, al ser sólo probables, garantizan la falsedad objetiva de la hipótesis incompatible con ellas. Pero una sola de ellas, si es aceptada como verdadera, es suficiente para excluir la decisión del juez sobre la verdad de la hipótesis y para basar, conforme al criterio de la coherencia, la decisión sobre su falsedad. La libre convicción, en consecuencia, mientras que puede superar las pruebas (necesarias pero no suficientes para justificar la condena), no puede superar las contrapruebas (suficientes pero no necesarias para justificar la absolución). ${ }^{21}$

El derecho de defensa no es sólo un derecho público subjetivo del imputado, sino que constituye también una exigencia esencial, en la estructura del proceso, ya que, éste no puede concebirse sin la defensa, en virtud, que deben contradecirse dialécticamente las partes con las hipótesis de la acusación con sus correspondientes pruebas, otorgando a la defensa los mismos derechos y facultades que a la acusación, es decir, resguardar efectivamente el equilibrio procesal entre las partes contendientes. ${ }^{22}$

Por lo que se puede decir que el derecho de defenderse es aquél que tiene el procesado para oponerse a la acusación. El concepto de defensa, junto con las nociones de acción y jurisdicción, son los tres pilares básicos sobre los que descansa la idea misma del proceso penal como estructura normativa destinada a armonizar la pretensión punitiva del Estado, la libertad individual y las exigencias de la correcta y válida administración de justicia dentro del Estado de Derecho.

\footnotetext{
${ }^{19}$ PAVA LUGO, Mauricio, op. cit., nota 13, p. 41.

${ }^{20}$ Ibídem, p. 42.

${ }^{21}$ FERRAJOLI, Luigi, Derecho y Razón. Teoría del garantismo penal, trad. Perfecto Andrés Ibañez, Alfonso RUIZ Miguel, Juan Carlos BAYÓN MOHINO, Juan TERRADILLOS BASOCO y Rocío CANTARERO BANDRÉS, Madrid, Editorial Trotta, 1998, colección Estructuras y Procesos, p. 151.

${ }^{22}$ CÁRDENAS RIOSECO, Raúl F., op. cit., nota 3, p. 8.
} 
Efectivamente, en Italia, Gaetano Foschini, citado por Alex Carocca Pérez, sostiene que "[...] el juicio presupone una duda sobre la cual debe recaer la decisión y la duda implica necesariamente dos antitéticas opiniones, entre las cuales se halla la alternativa verdadera. ${ }^{23}$ "La acusación y la defensa no son más imprescindibles polos dialécticos, por lo cual uno no tendría significado ni valor sin el otro". ${ }^{4}$ También en Italia, Francesco Carnelluti considera que la defensa surge de la necesidad imprescindible de la naturaleza dialéctica del juicio, y que el juez estará en mejor situación de decidir cuánto más claramente "se le presenten delante dos soluciones posibles. El peligro es que la duda no se le presente, no que él sea atormentado por ella." 25

Una garantía de singular importancia como es el derecho de defensa en cada etapa del procedimiento y durante todo el proceso que se lleva a cabo, lleva consigo la necesidad de accesar y garantizar, en sí mismo, el principio de contradicción para el perfeccionamiento y perseguir la finalidad de una justicia que exige la sociedad, al llevar de la mano a la víctima y ofendido durante todo su camino en el ámbito del ius puniendi, que tiene el Estado, para perseguir con ello, como dicen los autores latinoamericanos, una "igualdad de armas" al otorgar posibilidades de defensa y participación a los sujetos procesales por igual.

A modo de corolario, se puede afirmar en palabras de Sergio Gabriel Torres, que en el juicio oral la contradicción entre el acusador y el acusado adquiere fundamental importancia al posibilitar a las partes el pleno contralor recíproco de las probanzas presentadas en el proceso y una directa oposición de argumentos y alegatos allí interpuestos. De esta manera, es decir, posibilitando el desarrollo de un debate oral ampliamente contradictorio, se garantiza la observancia de la garantía constitucional de defensa en juicio que exige, sustancialmente en lo que nos ocupa, que el órgano jurisdiccional no dicte una resolución sin antes poder valorar la defensa que pueda ejercer quien en definitiva resulte acusado en el juicio. $^{26}$

Calamandrei, Carnelutti, Bellavista y Florián, coinciden en atribuir una importancia fundamental al principio de contradicción, hasta el punto que dicen que es a través de este derecho, que se logra desarrollar la finalidad del proceso penal, cual es la búsqueda de la verdad, pero tal afirmación no puede ser de recibo, pues lo que el proceso pretende es resolver el conflicto, y sólo lo puede hacer, a través, de lo que las partes logren probar por medio de sus alegaciones; correspondan o no a la verdad material, lo que por otra vía, casi siempre es imposible de verificar. En verdad, lo único que vale es el juicio jurisdiccional obtenido, a través, de un proceso que cumple con unas formalidades mínimas, que actualmente están recogidas en garantías constitucionales, destacándose, la de la defensa, que a su vez, nos lleva a identificar la de la contradicción. Todo esto, nos permite afirmar que el proceso en cuanto se permite la efectiva participación y en igualdad de condiciones a todos los sujetos que participan, podría constituir el mejor método para resolver el conflicto, permitiendo llegar a soluciones sociales más aceptables.

\footnotetext{
${ }^{23}$ Ídem, p. 8.

${ }^{24}$ Ibídem, p. 9.

${ }^{25}$ Ídem, p. 9

${ }^{26}$ GABRIEL TORRES, Sergio et al, Principio general del juicio oral penal, México D. F., Flores Editor y Distribuidor S. A. de C. V., 2006, p. 51.
} 


\section{EL DEFENSOR}

En sentido formal, la defensa es obra del defensor, que por su carácter técnico penetra al terreno de los hechos y del derecho, que se debe cumplir mediante alegaciones, oposiciones e impugnaciones argumentativas dirigidas al proceso, a fin, de presentar al tribunal las conclusiones aptas para la obtención de una sentencia acorde a una defensa adecuada.

Por lo que se puede aducir según palabras de Andrés Baytelman y Mauricio Duce, que en todo caso, debemos tener claro que litigar dentro del sistema acusatorio requiere de una formación específica y de una disciplina, que lejos de consistir en técnicas de oratoria o desarrollos de la capacidad histriónica, como los prejuicios de nuestra comunidad jurídica suelen creer. En cambio subyace la idea de que el juicio es un ejercicio profundamente estratégico y que, en consecuencia, comportarse profesionalmente respecto de él consiste - en particular para los abogados, aunque esta visión también altera radicalmente la actuación de los jueces- en construir una teoría del caso adecuada y dominar la técnica para ejecutarla con efectividad. El litigante en el juicio oral, en fin, debe narrar y persuadir ${ }^{27}$, a lo anterior, se considera ligado una argumentación jurídica, fáctica, dogmática y probatoria.

Por lo que para la eficacia en la elección y preparación de la metodología para el litigio dentro de juicio, junto con la comprobación de la teoría del caso, su controversia y su explicación de manera técnica y de facto entre los sujetos procesales, es lo que dará la concreción efectiva de la estrategia para litigar dentro del juicio oral; que conllevará al juez a tomar la decisión a favor de quien plantee y compruebe fehacientemente su teoría del caso con las proposiciones fácticas o enunciaciones mas acercadas a la realidad del caso planteado, para resolver con ello, los más apegado a derecho y sintetizar con lo expuesto, fundado y analizado en juicio, la síntesis del proceso como parte de la estrategia, de la cual, también forma parte imprescindible el juzgador para la concreción elemental del convencimiento con argumentos jurídicos en la estrategia de cualquiera de los sujetos procesales.

Expresa Ferrajoli, que para que la contienda se desarrolle lealmente y con igualdad de armas, es necesaria, por otro lado, la perfecta igualdad de las partes: en primer lugar, que la defensa esté dotada de la misma capacidad y de los mismos poderes que la acusación; en segundo lugar, que se admita su papel contradictor en todo momento y grado del procedimiento y en relación con cualquier acto probatorio, de los experimentos judiciales y las pericias al interrogatorio del imputado, desde los reconocimientos hasta las declaraciones testificales y los careos. La primera de estas dos condiciones exige que el imputado esté asistido por un defensor en situación de competir con el ministerio público. En un ordenamiento cuyas "leyes fuesen tan sencillas que su conocimiento estuviese al alcance de todos los ciudadanos", escribió Bentham, cada cual podría "dirigir y defender su causa en justicia como administra y dirige sus demás negocios" y sería por tanto suficiente la auto-defensa. Pero "en el reinado de una legislación oscura y complicada, de un modo de enjuiciar lleno de fórmulas y cargado de nulidades", es necesaria la defensa técnica de un abogado de profesión "para restablecer la igualdad entre las partes, respecto a la capacidad y para compensar la desventaja inherente a la inferioridad de condición" del imputado. Fue precisamente, con las reformas ilustradas cuando la defensa técnica, reducida durante siglos por la inquisición a "un arte baja de intrigas", asumió la forma moderna de la asistencia legal obligatoria. Naturalmente, "defensa técnica obligatoria" no quiere decir que la asistencia de un abogado do-

\footnotetext{
${ }^{27}$ BAYTELMAN, Andrés y Duce, Mauricio, Litigación penal. Juicio oral y prueba, 2a. ed., México, Fondo de Cultura Económica, 2009, p. 31.
} 
tado de capacidad profesional sea una obligación para el imputado, sino que es un derecho, al que puede renunciar libremente, sin perjuicio de la obligación del estado de asegurarla gratuitamente si aquél no dispone de medios para beneficiarse de ella. En lo que respecta a la paridad de poderes, es claro que supone que la acusación pública no tenga ningún poder sobre el imputado, pues todos los poderes de una parte sobre la otra acaban por "darles muerte a las libertades civiles"; pero exigiría también, la defensa pública de un magistrado, junto a la defensa profesional del defensor, subordinada a sus estrategias defensivas, pero dotada de las mismas funciones y potestades investigadoras que el Ministerio Público.

El pensamiento ilustrado, en coherencia con la opción acusatoria, reivindica la presencia de uno y otro en todas las actividades probatorias. Voltaire protestó contra la posibilidad de que el careo entre el imputado y los testigos de la acusación quedase a la discrecionalidad del juez en lugar de ser algo obligatorio. Filangieri sostuvo que, al imputado, el legislador "debería permitirle que contase con el auxilio de uno o más abogados en todos los trámites del proceso". Bentham propugnó la presencia del defensor en el interrogatorio no sólo del imputado sino también de los testigos. Y otro tanto hizo Pagano, que quiso que los testigos de la acusación "se interrogaran ex integro en presencia del reo" y subrayó "cuánto ayuda a conocer la verdad esa contradicción”. ${ }^{2}$

Por lo que se puede sostener o precisar, que el derecho de defensa se debe regular como garantizar por el Estado, tanto en la forma en que se ejerce como en la calidad de quien lo ejerza, ello, en favor de la persona, cuidando que no solamente se pueda ejercer por un licenciado en derecho o por el imputado "autodefensa", sino que se garantice que ese defensor público o privado, se encuentre obligatoria y debidamente capacitado y certificado siempre que se respete su autonomía.

\section{LA DEFENSA TÉCNICA}

Es indudable, que uno de los grandes triunfos del derecho garantista, es que todo inculpado se encuentre asistido y defendido por un profesional del derecho desde las primeras diligencias hasta la conclusión del juicio. Por ello, si no puede designar un defensor, el Estado le proporcionará uno. Ahora bien, se entiende por ese solo acto, que goza de una defensa legal, sin embargo, resulta de suma importancia distinguir que el derecho de gozar de un defensor tiene dos grandes aspectos, el primero, que le sea otorgado el derecho de designar su defensor, pero el segundo aspecto, es el de mayor significación, que ese profesional esté debidamente capacitado para defenderlo, ya que, en caso contrario podrá contar con una defensa legal, pero no técnica. ${ }^{29}$

Por lo anterior, el Estado debe apegarse a que la garantía y respeto del derecho de defensa no se haga ilusoria, de tal manera, que quien no posea los medios para conseguir un defensor, el Estado le proporcione uno de oficio; de lo contrario no podría tener fundamento el derecho de defensa, por lo cual, el debido proceso estaría viciado en sus más fundamentales garantías. El ideal, es que exista, entre las partes que controvierten en el proceso, en sus puntos de vista, un equilibrio, lo cual, es muy difícil de lograr dado la calidad de las partes. Es por lo anterior, que siempre se entiende que la eficacia del contradictorio supone el equilibrio de los contradictores, condición esa que aunque difícil de conseguir no es imposible de alcanzar bajo el aspecto de la calidad de los contradictores.

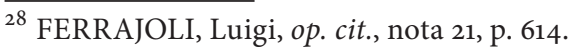

${ }^{29}$ ORONOZ SANTANA, Carlos M., Tratado del juicio oral, México D. F., PACJ, 2009, p. 4.
} 
Por lo que un sistema penal acusatorio que se instituya como un modelo de procesamiento criminal en donde la "igualdad de armas" entre la acusación y la defensa constituya fundamento sustancial de su estructura y efectividad, bajo el concepto de que al ser "adversarial" o "de partes" logrará que tanto la acusación como la defensa se presenten en igualdad de condiciones ante un juez, que final y rápidamente dirimirá el conflicto, inclinándose por aquella parte que mejor hubiese argumentado y construido racionalmente su caso, no es más que una utopía al persistir una enorme distancia entre la teoría jurídica y la práctica judicial, como quiera que sea, estamos ante un sistema de procesamiento criminal con inmensas carencias, vicios y prejuicios, no siempre, con seguridad, imputables a los individuos que se esfuerzan por administrar justicia, puesto que, las realidades materiales de nuestro contexto histórico las superan, no podemos dejar de seguir aspirando a un proceso penal democrático, participativo, garantista y efectivo.

Para que la defensa llegue con un verdadero equilibrio al juicio o a las otras audiencias de decisión jurisdiccional, es preciso, que se le concedan, respetando claro está, los principios de necesidad, ponderación y proporcionalidad, similares oportunidades a las de la Fiscalía en la preparación de su caso. Máxime cuando la defensa no tiene derecho reconocido a conocer la totalidad de la evidencia sino hasta la audiencia de lectura de acusación, como que la Fiscalía podría estar adelantando una indagación por un tiempo bastante amplio (años incluso) sin que la defensa se enterara, pues solo existe obligación de comunicarle al ciudadano la actuación que en su contra se surte al momento de formularle la imputación en la audiencia que se dispone para tal efecto. ${ }^{30}$

Para que el sistema acusatorio garantice una aproximación al criterio de igualdad entre las partes, la defensa debe contar: con la posibilidad de poder indagar e investigar materialmente en las mismas condiciones que lo hace la Fiscalía. Con el despliegue de talento humano y de medios, que le permita ejercer objetivamente el principio de contradicción y la refutación de los elementos materiales probatorios o de los testigos con que cuenta el Estado. ${ }^{31}$

La facultad otorgada a la defensa relacionada con la actividad probatoria se enmarca en la lógica del sistema acusatorio, y debe ser interpretada de manera sistemática dentro del marco constitucional y legal. En la búsqueda de la verdad en el proceso penal se confrontan varios derechos y deberes. En cuanto a los derechos, en primer lugar el derecho a la defensa del imputado, el derecho a la verdad de la sociedad, el derecho de los ciudadanos a un pronta y recta justicia., los derechos de las víctimas, que cada vez cobra mayor relevancia y por supuesto la prevalencia de los derechos inalienables de las personas sean estas intervinientes o terceros. ${ }^{32}$ "La facultad investigativa de la defensa implica importantes retos que implica robustecer la idea de una paridad, de un equilibrio entre la acusación y la defensa." 33

Las exigencias que plantean los sistemas adversariales latinoamericanos sobre la defensa son mayores que aquellas que devienen del juzgamiento escrito, secreto y con investigación de carácter judicial. La razón es, que el sistema tradicional, escrito y sin publicidad real, es ampliamente tolerante con la mediocridad, debido a que permite espacios para suplir el desconocimiento por parte de todos los actores; no contiene estímulos para que el juez y las partes sientan comprometido su prestigio por actuaciones mediocres, debido a la poca visibilidad que tienen las actuaciones escritas, y por ende, los errores o aciertos que en ellas

\footnotetext{
${ }^{30}$ PAVA LUGO, Mauricio, op. cit., nota 13, pp. 51-52.

${ }^{31}$ I bídem, p. 60.

${ }^{32}$ PAVA LUGO, Mauricio, op. cit., nota 13, pp. 71-72.

${ }^{33}$ Ibídem, p. 110.
} 
se cometen. ${ }^{34} \mathrm{El}$ sistema acusatorio pone por primera vez a las partes a litigar casos en audiencias orales, en donde las decisiones se juegan realmente en el trabajo efectivo con la prueba y la argumentación jurídica. De muchas maneras, esta labor hace de la profesión de abogados y jueces algo profesionalmente muy atractivo y estimulante.35 Es por ello, que la preparación y capacitación constante de la defensa en las destrezas de litigación oral en un contexto de estudio jurídico, técnico, argumentativo y científico-dogmático con relación al caso que atienda, es parte de fondo "clave" para augurar el éxito en nuestra prosecución de una efectiva aplicación práctica de la defensa.

Los juicios orales no son un "concurso de oratoria" ni una "influencia extranjerizante", como han señalado rancios guardianes de una tradición autoritaria, sino un método dialéctico, abierto y democrático de encontrar la verdad y de validar ante los actores del proceso y la sociedad las resoluciones de un tribunal..$^{36}$ Los abogados tendrán que argumentar-y los jueces tendrán que tomar decisiones y justificarlas-instantáneamente y en público, en un contexto en que toda la comunidad estará al tanto de-y dispuesta a discutir-los pormenores de un caso que convoque su atención. ${ }^{37}$

El sistema incentivará a que, en un entorno de juego justo, los abogados exploren todas las armas legales disponibles, investiguen todos los hechos desconfíen de toda la información (y, por lo tanto, la verifiquen), detecten todas y cada una de las debilidades en el caso de la contraparte (argumentación y prueba), construyan su propio caso sobre la base de que la contraparte hará lo mismo y, en consecuencia, cada defecto del caso propio implicará un mayor riesgo de perder. Si los abogados no están preparados, los casos se pierden y se pierden ante los ojos de todo el mundo; si los jueces no están preparados, las injusticias que ello genera se cometen ante los ojos de todo el mundo. ${ }^{38}$ El juicio es un ejercicio profundamente estratégico y que, en consecuencia, comportarse profesionalmente respecto de él consiste - en particular para los abogados, aunque esta visión también altera radicalmente la actuación de los jueces - en construir una teoría del caso adecuada y dominar la técnica para ejecutarla con efectividad. ${ }^{39}$

La tarea de litigar puede traducirse en la de proveer al juez un relato verosímil que le dé fundamento a una decisión a nuestro favor. Puede fraccionarse en tres habilidades para litigar efectivamente en juicios orales. La primera de ellas está vinculada al desarrollo de una capacidad para planificar estratégicamente el juicio y su preparación (“teoría del caso"). La segunda habilidad tiene que ver con la capacidad para obtener e introducir información de manera efectiva en el juicio (exámenes y contraexámenes de testigos y peritos, y las demás actividades asociadas a tales cuestiones). Finalmente, un tercer nivel de habilidad es el uso efectivo de la información que se producirá o que ya se haya producido en juicio (alegatos de apertura y clausura). ${ }^{40}$

La principal labor del defensor es ejercitar la defensa técnica de quien requiere sus servicios, ya sea público o privado. Debe buscar el respeto en todo momento de los derechos y garantías que le corresponden. En este sistema debemos buscar la profesionalización y

\footnotetext{
${ }^{34}$ BINDER, Alberto et al., op. cit., nota 15, p. 36.

${ }^{35}$ BAYTELMAN, Andrés A. y Duce, Mauricio J., op. cit., nota 27, p. 33.

${ }^{36}$ Ibídem, pp. 21-22.

37 Ibid., pp. 28-29.

${ }^{38}$ Ibídem, pp. 28-29.

39 Ibid., p. 31.

${ }^{40}$ Ibídem, p. 36.
} 
certificación de los abogados en materia penal, a fin de garantizar el conocimiento y eficaz desempeño en beneficio de los usuarios de su servicio, así como, un código deontológico para que se ejerza con mayor responsabilidad nuestra profesión y sea reflejado en mayor confianza en el desempeño de los defensores públicos y privados.

Por lo que la defensa técnica precisa preferentemente que sea desempeñada por un defensor público o privado, como estratega para la defensa del inculpado y que abarque lo siguiente: conocimientos generalizados de ciencias forenses, investigador, gestor, director jurídico, guía de la investigación, protector de las garantías procesales, argumentador jurídico racional y conocedor del procedimiento penal. Sobre la presencia del defensor de manera técnica en todas las etapas del proceso, es importante señalar, que si se celebra alguna audiencia sin su presencia o con la presencia de un defensor público designado oficiosamente en el acto por el juez del conocimiento, en virtud, de la inasistencia del defensor particular nombrado por el inculpado, esto implicaría una violación a la garantía de defensa adecuada, por lo que en todo momento se debe tener cuidado sobre la manera en que se materialice el derecho de defensa por medio de la asistencia de un defensor capacitado y certificado constantemente.

\section{PRINCIPIOS CONSUSTANCIALES AL DERECHO DE DEFENSA}

La oralidad, la inmediación, la concentración y la contradicción, son los postulados sobre los cuales se erige la plena convicción y criterio de conciencia del juzgador para la aplicación de la sana crítica en su juicio de valor. La contradicción que ejerce la defensa, es el elemento que permite ejercer simultáneamente y en forma recíproca el contralor de la actividad procesal y la contraposición de los argumentos, razones y fundamentaciones de las partes intervinientes sobre las diversas cuestiones introducidas en el debate, es por ello, la importancia trascendental de desempeñar una defensa técnica adecuada y de calidad a las necesidades del sistema penal. Se asegura así, entonces, la igualdad y equilibrio en las atribuciones, derechos y obligaciones de los distintos sujetos procesales. Va de suyo, que la oposición de los argumentos debe ser razonablemente fundada, oportuna y jurídicamente adecuada. Por lo que en palabras de Jorge L. Frank, el principio de contradicción inherente a la defensa "se hace plenamente visible en el acto de la acusación fiscal y con el alegato de la defensa, donde cada uno de ellos hace la merituación de la prueba producida, interpretada en forma analítica y sintética, con un fundamento científico-técnico-jurídico ${ }^{41}$

Por lo que en palabras de Andrés Baytelman y Mauricio Duce, es necesario "un proceso penal plenamente acusatorio que permita garantizar la contradicción y la igualdad entre las partes que permitan articular un proceso dialéctico de valoración de la prueba para conocer la verdad de los hechos, a partir, de la presentación de pruebas y argumentos de manera equilibrada y en igualdad de circunstancias entre la defensa y el Ministerio Público. ${ }^{42}$ Es preciso, un proceso en el que el juzgador está obligado a resolver y dar solución jurídica a cualquier caso con base en las normas, argumentaciones, contra argumentaciones, principios y directrices que garanticen por sí mismos el procedimiento, y que ofrecen respecto del caso en particular y de las partes, contribuyendo al esclarecimiento del caso e induciendo a la verdad jurídica, misma, que a pesar de la oscuridad, contradicción o deficiencias de la ley se debe de resolver.

\footnotetext{
${ }^{41}$ FRANK, Jorge L. Sistema acusatorio criminal y juicio oral, Buenos Aires, Lerner editores asociados, 1986, p. 36.

$4^{2}$ BAYTELMAN, Andrés A. y Duce, Mauricio J., op. cit., nota 27, p. 19.
} 
Si bien se han llegado a reconocer ciertos principios a favor del inculpado, como el de debido proceso, presunción de inocencia, legalidad, entre otros, es necesario puntualizar que todavía no se ha contextualizado ampliamente sobre el derecho de defensa adecuada, aunque se hace notar que ya se formado un tanto democrático el procedimiento penal con objetivos sociales, y con ciertas garantías para las partes que intervienen en el procedimiento.

\section{INVIOLABILIDAD DE LA DEFENSA PARA UNA “IGUALDAD DE ARMAS”.}

Considerando que el juicio es adversarial y contradictorio, resulta necesario que las partes se encuentren en igualdad de condiciones, es decir, como dicen los autores sudamericanos, "en igualdad de armas", por ello, en palabras de Carlos Oronoz Santana, es posible establecer "la prohibición para los jueces, para que no mantengan comunicación directa o indirecta con alguna de las partes o sus defensores sobre los asuntos encomendados, por lo tanto, ello no significa que no pueda entablar alguna comunicación, pero si lo hace con una de las partes, la otra tendrá el mismo derecho, lo anterior permitirá evitar la parcialidad. ${ }^{43}$ Este es un derecho que se debe mantener durante todas las etapas del proceso, en tanto la defensa del inculpado es inviolable, correspondiendo la obligación de los jueces de garantizarla sin preferencias y sin desigualdades." ${ }^{44}$

En palabras de Carnelutti, "el imperativo del principio de contradicción requerido en el juicio oral reside en la obligatoriedad de la asistencia jurídica del acusado. Este derecho a la tutela judicial efectiva reconocido por los distintos tratados internacionales comporta la exigencia de que, en ningún momento, pueda producirse indefensión del inculpado, lo que analizado en relación con el reconocimiento del derecho de defensa, implica que en todo proceso penal oral debe respetarse el derecho de defensa contradictoria de las partes contendientes, a quienes debe darse, la ya mencionada, oportunidad de alegar y probar procesalmente sus derechos por sí mismos - para el caso que correspondiera-o con la asistencia de un letrado. ${ }^{45} \mathrm{La}$ exigencia de la defensa hunde sus raíces en las inexplorables profundidades del mecanismo de la conciencia. La dignidad del defensor, decía, se eleva justamente, pero se agrava no menos la responsabilidad de él." ${ }^{46}$

En palabras de Francesco Carrara, "la necesidad de la defensa es la causa primera del derecho de punir. La justicia determina los límites y la medida del mismo. La necesidad de la defensa no basta para legitimar la irrogación de una pena contra el que no violó los preceptos de la justicia. La ciencia de derecho penal no es, por lo tanto, una ciencia con la cual se ande buscando lo que a uno y a otro le place establecer. Es el desenvolvimiento de principios de razón eterna; es la búsqueda de verdades absolutas." ${ }^{7}$

El fundamento del derecho penal es la tutela jurídica. Es un desenvolvimiento necesario de esta idea que cuando no existe violación de derechos, la espada de la justicia no puede descargar sus golpes. Consecuencia de tales principios, es que el derecho penal no sea, en manera alguna, el enemigo y el moderador de la libertad humana, sino que sea, por el contrario, el protector, por el guardián de ella; en una palabra, el complemento de la eterna ley

\footnotetext{
${ }^{43}$ ORONOZ SANTANA, Carlos M., op. cit., nota 24, p. 3.

${ }^{44}$ Idem.

${ }^{45}$ GABRIEL TORRES, Sergio, et al, op. cit., nota 21, p.51.

${ }^{46}$ CARNELUTTI, Francesco. Cuestiones sobre el proceso penal, México D. F., Harla, 1997, Series Clásicos del derecho procesal penal, Vol. 2, p. 101.

47 CARRARA, Francesco, Derecho Penal, México D. F., Oxford, 2003, biblioteca clásicos del derecho, Vol. 3, pp. 35-36.
} 
del orden que dotó al hombre de derechos y que quiso que esos derechos no sean perjudicados ni por una fuerza privada, ni por una potestad pública. Cuando una criatura humana no ha atentado contra el derecho de otra, razón tiene de exigir que no se atente contra su persona y de gritar que es injusta la mano, cualquiera que ella sea, que pretende golpearla. ${ }^{48}$ " $\mathrm{La}$ defensa del derecho no es completa si no se muestra eficaz respecto a todos, vale decir, tanto respecto al que violó la ley, como respecto a aquellos que no la transgredieron todavía."49

Es preciso, hacer una mención especial a la filosofía de los derechos humanos dentro del proceso acusatorio, que se caracteriza básicamente por tener como centro de todos sus fundamentos al hombre. Igualmente por construir una barrera que pone freno a los abusos del poder, precisamente en defensa de los intereses del hombre, que constituye su razón de ser. Los derechos humanos son de tan alto rango que por su parte protegen los derechos a actuar en condiciones de igualdad frente a las demás partes y a ser oído públicamente por un tribunal independiente e imparcial, el derecho del acusado a no ser sometido a torturas, ni a tratos crueles, inhumanos o degradantes, derecho a conocer detalladamente la acusación formulada, derecho a estar presente en el proceso, derecho a recoger las pruebas y a intervenir en su práctica, interrogando a los testigos, peritos y demás medios de prueba posibles, derecho a la libertad durante todo el proceso y el derecho a defenderse. Es por ello, que el Estado debe velar por la procuración de los derechos humanos para garantizar la inviolabilidad de "la igualdad de armas".

Una de las finalidades del derecho garantista, es que todo inculpado se encuentre asistido y defendido por un profesional del derecho desde las primeras diligencias hasta la conclusión del juicio. Por ello, si no puede designar un defensor, el Estado le proporcionará uno público. Ahora bien, se entiende que por solo ese acto se goza de una defensa legal, sin embargo, resulta de suma importancia distinguir que el derecho de gozar de un defensor tiene dos vertientes, el primero, el que le sea otorgado el derecho de designar a su defensor como lo es un profesionista abogado, pero la segunda vertiente que es la más trascendental y que adquiere en el proceso mayor significación, es que ese defensor esté debidamente capacitado para defenderlo, no basta tener un título de licenciado en Derecho, se requiere que ese profesional se encuentre debidamente capacitado para que se cuente no solamente con una defensa legal, sino también técnica que garantice al inculpado su derecho a defensa adecuada con el carácter de técnica al proceso y a sus necesidades legales. Ahora bien, esto es de suma importancia por los derechos y facultades que tiene el inculpado para acceder a pruebas, contradecirlas, presentar testigos y demás facultades que podrán ser ejercitadas.

En palabras de Jorge Claría, "como derivado del contradictorio, la correcta regulación de la defensa favorece la regla del equilibrio procesal entre las partes oponentes proponiendo formalmente a la igualdad de oportunidades. A su vez, ese equilibrio permite que ingresen al proceso elementos probatorios y técnicos de descargo como necesarios ingredientes para una más justa aplicación del derecho sustantivo, y evita que en el proceso se introduzcan actos o se cumplan trámites con descuido de los presupuestos o requisitos que deben observarse." 50

\footnotetext{
${ }^{48}$ Ibídem, p. 76.

49 Ídem.

50 CLARÍA, O. Jorge A., Derecho Procesal Penal, t I, Buenos Aires, Rubinzal-Culzoni editores, 1998, p. 280. 
La dogmática jurídica es aplicable a todos los campos del derecho y genera diversas teorías que seguramente contribuirán a la construcción de un debate técnico y una defensa adecuada, al ordenar, sistematizar, regular y unificar la construcción de la teoría del caso, en el debate contradictorio de manera científica y, que sin duda, complementará y perfeccionará, la argumentación jurídica.

Podríamos definir a la dogmática jurídica en palabras de Luis Felipe Agripino, como "el análisis sistemático, ordenado, completo e integral de los textos legales. Dicho análisis permite desentrañar las instituciones jurídicas y en esa medida, proporcionar seguridad jurídica a los destinatarios del Derecho positivo." 51 Es así, como se debe poner en la mesa de análisis los diferentes conceptos en que se basa la investigación y que tienen, todos ellos, antecedentes desde los orígenes de la organización del Estado hasta su relación íntima con un efectivo y eficiente sistema procesal penal, por lo cual, la reforma al sistema penal debe atender también a la dogmática jurídica para que se desarrolle integralmente y, se atienda la configuración y aplicación sistemática del delito.

Se ha dicho que la dogmática penal en este nuevo sistema de justicia penal desaparecerá; yo creo que quien considera ello es porque no la conoce y le parece el momento perfecto para enterrarla. Para todo el proceso penal bajo el principio de legalidad le viene bien la fundamentación y motivación sustantiva, por ello, la teoría del caso es el momento en que converge el derecho sustantivo en el derecho adjetivo.52 Los profesionistas que se dediquen a defender, acusar y resolver un caso dentro del sistema penal acusatorio, deben atender y dominar la dogmática junto con las habilidades y destrezas de la argumentación como vinculo inescindible y no sólo basarse en la retórica sin fondo, as-i como, en el procedimiento a seguir. Ya que, si bien estamos frente a otra manera de impartir justicia es inconcuso su debida aplicación para salvaguardar principios como el derecho de defensa adecuada y se precisa la preparación de los abogados no solo procesalmente, sino también dogmáticamente, para que se aplique justicia de manera más adecuada hasta la debida comprobación del hecho punible.

\section{CONCLUSIONES}

Primera. El derecho de defensa adecuada es un principio que se debe comprender por la comunidad y que se debe adecuar, regular e interpretar de manera efectiva para su optimización.

Segunda. Se debe velar en la ley por la especialización, profesionalización y capacitación de los defensores y ministerios públicos, ya que, no es suficiente aludir a un derecho de defensa adecuada en el texto constitucional, códigos sustantivos y adjetivos para que se ejerza adecuadamente, así como, por la creación de un código deontológico para los abogados.

\footnotetext{
${ }^{51}$ GUERRERO AGRIPINO, Luis Felipe, Teoría del delito y argumentación jurídica, México D. F., Azafrán y Cinabrio, 2010, p. 41.

52 BARDALES LAZCANO, Erika, Guía para el Estudio del Sistema Acusatorio en México, $3^{\mathrm{a}}$ ed., Magíster, México, 2010, p. 202.
} 
Tercera. Debe garantizarse la inviolabilidad del derecho de defensa desde la etapa preliminar hasta la conclusión del juicio oral.

Cuarta. La dogmática jurídico-penal es un vinculo inescindible con la ley procesal penal para el ejercicio de un derecho de defensa adecuada.

BIBLIOGRAFÍA.

ALEXY, Robert, Teoría de los derechos fundamentales, $2^{\text {a }}$ ed., trad. Carlos Bernal Pulido, Madrid, Centro de Estudios Políticos y Constitucionales.

ARIAS, Juan Carlos y CALDERÓN, Henry, Axiología y deontología del proceso penal y el precedente judicial, Colombia, Checchi And company consulting, 2002.

ARISTIZABAL BOTERO, Luis Ignacio, Contradicción o controversia de la prueba en materia penal, Bogotá D. C., Editorial Leyer, 2001.

BARDALES LAZCANO, Erika, Guía para el Estudio del Sistema Acusatorio en México, $3^{\mathrm{a}}$ ed., México D. F., Magíster, 2010.

BAYTELMAN, Andrés A. y DUCE, Mauricio J., Litigación penal. Juicio oral y prueba, $2^{\mathrm{a}}$ ed., México D. F., Fondo de Cultura Económica, 2009.

BINDER, Alberto, et al., Manual de defensoría penal pública para América Latina y el Caribe, Santiago, Alfabeta artes gráficas, 1985 .

CÁRDENAS RIOSECO, Raúl F. El derecho de defensa en materia penal, su reconocimiento constitucional, internacional y procesal, $2^{\mathrm{a}}$. ed., México D. F., Porrúa, 2009.

CARNELUTTI, Francesco. Cuestiones sobre el proceso penal, México, Harla, 1997, Series Clásicos del derecho procesal penal, vol. 2.

CARRARA, Francesco, Derecho Penal, México, Oxford, 2003, biblioteca clásicos del derecho, vol. 3 .

CLARÍA, O. Jorge A., Derecho Procesal Penal, t I, Buenos Aires, Rubinzal-Culzoni editores, 1998.

CHOWELL Arenas, Daniel Federico, Los principios del proceso penal. Su regulación y su realidad en el estado de Guanajuato, Guanajuato, Universidad de Guanajuato, 2008.

COURTIS, Christian, Miguel Carbonell (comp.), "Los derechos sociales en perspectiva: la cara jurídica de la política social”, Teoría del neoconstitucionalismo, Madrid, Editorial Trotta, 2007.

FERRAJOLI, Luigi, Derecho y Razón. Teoría del garantismo penal, trad. Perfecto Andrés Ibáñez, Alfonso Ruiz Miguel, Juan Carlos Bayón Mohino, Juan Terradillos Basoco y Rocío Cantarero Bandrés, Madrid, Editorial Trotta, 1998, colección Estructuras y Procesos.

- - - - D Derechos y garantías. La ley del más débil, $4^{\mathrm{a}}$ ed., trad. Perfecto Andrés Ibáñez y Andrea Greppi, Madrid, Editorial Trotta, 2004, colección Estructuras y Procesos. 
FRANK Jorge L., Sistema Acusatorio Criminal y Juicio Oral, Argentina, Lerner editores asociados, 1986.

FIX-ZAMUDIO, Héctor, Eduardo FERRER MAC-GREGOR, (coord.), "Breves reflexiones sobre el concepto y contenido del derechos procesal constitucional", Derecho procesal constitucional, $4^{\text {a }}$ ed., México, D.F., Porrúa., 2003, t. I.

GABRIEL TORRES, Sergio et al, Principios generales del juicio oral penal, México D. F., Flores Editor y Distribuidor S. A. de C. V., 2006.

GÓMEZ COLOMER, Juan-Luis, El sistema de enjuiciamiento criminal propio de un Estado de Derecho, México D. F., Instituto Nacional de Ciencias Penales, 2008, p. 204.

GUERRERO AGRIPINO, Luis Felipe, Teoría del delito y argumentación jurídica, México D. F., Azafrán y Cinabrio, 2012.

ORONOZ SANTANA, Carlos M., Tratado del Juicio Oral, México D. F., Publicaciones Administrativas Contables Jurídicas, S.A. de C.V., 2009.

PAVA LUGO, Mauricio, La defensa en el sistema acusatorio, Bogotá D. C., ediciones jurídicas Andrés Morales, 2009.

PICÓ I JUNOY, Joan, Las garantías constitucionales del proceso, Barcelona, José María Bosch Editor, 1997. 
